\title{
Reflexiones sobre las vivencias de estudiantes de posgrado de psiquiatría en un hospital psiquiátrico durante la
}

\section{Autores}

Martina Klenner

Médica. Residente de psiquiatría en Hospital Vilardebó.

\section{Leticia González}

Médica. Residente de psiquiatría en Hospital Vilardebó.

\section{Silena Correa}

Médica. Residente de psiquiatría en Hospital Vilardebó.

\section{Valentina Lanaro}

Médica. Residente de psiquiatría en Hospital Vilardebó.

\section{Mariana Rossi}

Médica. Posgrado de psiquiatría en Hospital Vilardebó.

\section{Silvana Martínez}

Médica. Posgrado de psiquiatría en Hospital Vilardebó.

Valeria Gómez de Freitas Médica. Residente de psiquiatría en Hospital Vilardebó.

\section{Diego Hernández}

Médico. Residente de psiquiatría en Hospital Vilardebó.

\section{Viviana Porto}

Asist. de la Clínica Psiquiátrica, Unidad Docente Asistencial Vilardebó.

\section{Paola Pereira}

Asist. de la Clínica Psiquiátrica, Unidad Docente Asistencial Vilardebó.

\section{Lía Redes}

Psiquiatra. Prof. Adj. de la Clínica Psiquiátrica, Unidad Docente Asistencial Vilardebó.

\section{Soledad Brescia}

Psiquiatra. Prof. Adj. de la Clínica Psiquiátrica, Unidad Docente Asistencial Vilardebó.

Margarita Wschebor

Psiquiatra. Prof. Agda. de la Clínica Psiquiátrica, Unidad Docente Asistencial Vilardebó.

Correspondencia:

martinaklenner1@gmail.com

\section{Resumen}

En Uruguay se registraron los primeros casos de covid-19 en marzo de 2020. El segundo brote de la enfermedad ocurrió, menos de un mes después, en el Hospital Vilardebó, centro psiquiátrico ubicado en la capital de nuestro país. El presente artículo se centra en nuestra vivencia como estudiantes de posgrado de psiquiatría durante la pandemia de covid-19 en dicho centro hospitalario. Esta pandemia ha significado un gran impacto para trabajadores y educandos de la salud, que tuvieron que lidiar con altos niveles de incertidumbre durante la práctica y reposicionarse en relación con los pacientes. Varios estudios hablan de las implicancias emocionales en los médicos, siendo los síntomas de ansiedad y depresión los más reportados. Similares emociones fueron experimentadas por los autores del presente artículo. No obstante, la experiencia implicó un aprendizaje en lo que respecta a la capacidad de adaptación y la importancia del trabajo grupal.

\section{Palabras clave}

pandemia

incertidumbre

vivencias

estudiantes de posgrado

pacientes

\section{Summary}

In Uruguay the first COVID-19 cases were registered in March 2020. The second outbreak occurred less than a month later at Hospital Vilardebó, the nationwide reference psychiatric hospital in the capital city. This article describes our experience as Psychiatry postgraduate students at Hospital Vilardebó during COVID-19 pandemic. This pandemic has had great impact on health workers and students, having to deal with high levels of uncertainty and having to change position regarding relationship with patients. Several studies mention emotional implications for doctors; anxiety and depression symptoms are the most reported. Similar emotions were experienced by the authors of this article. However, this also involved learning about adaptability and the importance of group work.

\section{Key words}

\author{
pandemic \\ uncertainty \\ experiences \\ postgraduate students \\ patients
}




\section{Introducción y marco teórico}

La infección causada por el coronavirus más recientemente descubierto, denominado formalmente como SARS-CoV-2, dio lugar a la pandemia de la enfermedad llamada covid-19.

El primer brote de covid-19 fue notificado en Wuhan (provincia de Hubei, China) el 31 de diciembre de 2019. ${ }^{1}$ El 30 de enero de 2020, tras la rápida expansión de la enfermedad, la Organización Mundial de la Salud declara la existencia de un riesgo de salud pública de interés internacional, y el 11 de marzo declara la enfermedad como pandemia. ${ }^{2}$ En octubre del mismo año, habían notificados 43.438 .043 casos confirmados y 1.158.596 muertes en el mundo por esta enfermedad, según los datos en tiempo real que nos ofrece el sitio web de la Johns Hopkins University. ${ }^{3}$

El primer caso de covid-19 en la región fue confirmado en Brasil el 26 de febrero de 2020. En nuestro país se detectaron los primeros casos positivos y se declaró la emergencia sanitaria el 13 de marzo, con un primer brote vinculado a un casamiento. Para ese entonces, ya contábamos con información de la alta contagiosidad del virus y de la evolución de los brotes epidemiológicos en otros países, por lo que el gobierno uruguayo exhortó a la población a tomar medidas de aislamiento social y distanciamiento físico, por lo cual la sociedad en su conjunto debió adoptar las modificaciones que se introdujeron en la cotidianidad. El segundo brote de la enfermedad en nuestro país ocurrió precisamente en el Hospital Vilardebó, centro psiquiátrico ubicado en la capital, donde los primeros casos positivos se notificaron el día 5 de abril. ${ }^{4}$

Uruguay enfrentó en el siglo xix brotes epidemiológicos que llevaron a miles de personas a la muerte y causaron graves problemas económicos. La prensa ha dedicado artículos a la historia de las epidemias en Uruguay, donde se habla de la fiebre amarilla y el cólera. En 1855 y 1857 transitamos los dos primeros brotes de fiebre amarilla, con más de 3000 personas fallecidas en un Montevideo que por aquel entonces tenía 20.000 habitantes.
El segundo brote, en 1857, le costó la vida al Dr. Teodoro Vilardebó, quien da nombre a nuestro hospital. ${ }^{*} 5$ Una nueva epidemia de esta enfermedad ocurrió en 1872, esta vez con 500 fallecidos. Si bien la ciudad ya contaba con otra infraestructura asistencial, esta fue desbordada.

Entre estas dos últimas epidemias ocurrió la del cólera. Las medidas de salubridad pública ante esta enfermedad fueron drásticas: prohibición de velatorios, desalojo de conventillos, prohibición de lavado de ropa en playa Pocitos, cuarentena estricta de los recién llegados al país (en la Isla de Flores) y aislamiento de los enfermos. El brote terminó con la vida de 535 personas y enfermó a unas 1317.

A principios del siglo xx, la pandemia por la gripe española fue el más reciente antecedente de la pandemia actual. En ese entonces (19181919), el Consejo Nacional de Higiene decidió tomar medidas estrictas de control sanitario a las personas en tránsito en las fronteras, realizó desinfección de espacios públicos, limitó las reuniones y decidió el cierre de centros educativos, teatros y cines. Se estima que fallecieron más de 6000 personas en una población de 1.4 millones de habitantes. ${ }^{6}$

No hemos encontrado referencias históricas que describan las vivencias de los trabajadores de la salud mental ni de los pacientes durante estas epidemias.

El presente artículo hace referencia a nuestra vivencia como grupo de estudiantes de posgrado de psiquiatría en el Hospital Vilardebó, durante la pandemia de covid-19. Luego de cursar los dos primeros años de formación en diferentes centros (Hospital Maciel, Hospital Pasteur y Hospital de Clínicas), nos encontramos desde el 1 de abril en el Hospital Vilardebó para cursar, como es tradición, el tercer y último año. Cuatro días después de nuestra llegada, se conoció el primer caso positivo en dicho centro.

Tras la aparición de casos positivos, el hospital debió implementar medidas estrictas para hacer frente al brote epidemiológico. Se estableció la utilización obligatoria de equipos de protección personal específicos
* Luego de graduarse como médico en París, Vilardebó volvió al Uruguay del siglo XIX a ejercer la profesión. Ante la fiebre amarilla, más de la mitad de la población de la ciudad huyó hacia las quintas, a la campaña o a Buenos Aires. Vilardebó se quedó y murió, a los 52 años de edad, peleando con una enfermedad que nunca terminó de conocer ni curar. 
para ingresar a las salas y circular dentro del hospital. La emergencia cerró sus puertas por un período de dos semanas, viéndose interrumpido el ingreso de nuevos pacientes. Las altas hospitalarias fueron postergadas por un período de un mes y las visitas a los pacientes internados se encuentran suspendidas hasta el día de hoy. Las instalaciones del hospital fueron reorganizadas; se asignaron salas de aislamiento para pacientes diagnosticados como positivos y para pacientes sospechosos. Las actividades grupales, como las terapias psicológicas y ocupacionales, fueron suspendidas durante el tiempo que duró el brote, así como la electroconvulsoterapia, debido al riesgo de contagio que podía implicar la técnica. Con los pacientes a los que se asistía de forma ambulatoria en las policlínicas del hospital, se utilizó el recurso de la telemedicina, en vistas a garantizar la continuidad asistencial.

Como otros servicios de formación médica en el mundo, ${ }^{7,8}$ la unidad docente-asistencial de la cátedra de psiquiatría de la Universidad de la República (Udelar) debió también implementar múltiples modificaciones en la organización del servicio. Las salas habituales de atención fueron reasignadas y se priorizó la actividad asistencial, que comenzó a llevarse a cabo por una dupla conformada por un docente y un estudiante de posgrado. La atención de los pacientes ambulatorios pasó a ser realizada vía telefónica. Las instancias colectivas presenciales fueron suspendidas y se implementaron clases y reuniones de equipo en modalidad virtual con fines académicos y de contención.

Todas estas medidas tuvieron sus repercusiones. La noticia de la postergación de las altas significó un estresor que repercutió negativamente en la mayoría de los pacientes, principalmente en aquellos que se encontraban en condiciones clínicas de egreso y tenían la expectativa de reunirse a la brevedad con su entorno familiar. Todos los pacientes hospitalizados sufrieron la repentina interrupción del contacto con el exterior, con dificultades para comunicarse incluso telefónicamente con sus seres queridos. Se les impuso una realidad nueva, inesperada y difícil de comprender. La incertidumbre en cuanto a la evolución de la situación, acompañada de una exigencia adaptativa en pacientes que ya estaban ante una situación estresante, implicó un grado de angustia que en muchos casos desbordó la posibilidad de afrontamiento individual. Esto significó un desafío para un equipo de salud que se encontraba también en situación de vulnerabilidad y constante adaptación.

El equipo de salud se enfrentó a la necesidad de ejercer el rol de una manera completamente distinta y desconocida. La propia angustia debió ser postergada o redirigida ante la necesidad de estar disponibles para brindar contención y apoyo a los pacientes.

Los estudiantes cursando en modalidad de posgrado tuvieron que dejar de concurrir al hospital, con la suspensión casi total de la actividad académica a excepción de las instancias virtuales. Para los que cursan con cargo de residente, que siguieron concurriendo al hospital, la tarea se volvió solitaria.

Debimos reaprender a vincularnos con nuestros pacientes, usando equipos de protección personal que nos cubrían el rostro y el cuerpo por completo, que nos limitaban la capacidad de expresión en momentos en que la sentíamos más necesaria que de costumbre. Al día de hoy sabemos que hubo 40 pacientes y 21 funcionarios contagiados, de los cuales solo 4 debieron ser trasladados a otro centro por requerir asistencia especializada, y ninguno falleció por la enfermedad.

Hoy, meses después del inicio de esta experiencia, podemos afirmar que nadie salió indemne. Fue y es una etapa de crisis, pero también de aprendizaje, por lo que consideramos enriquecedor compartir el relato de esta experiencia desde la perspectiva del equipo de estudiantes de posgrado de psiquiatría de la Facultad de Medicina, que ha asistido a los pacientes del Hospital Vilardebó desde el 1 de abril hasta la fecha.

Como objetivo, nos planteamos sistematizar nuestras experiencias como estudiantes de posgrado durante el brote de covid-19 en el Hospital Vilardebó en un contexto de pande- 
mia, con el fin de transmitir nuestro registro vivencial de la experiencia.

\section{Materiales y métodos}

La consigna consistió en la elaboración de relatos escritos en forma abierta e individual, en los que cada uno expresó su vivencia durante la pandemia en este período formativo.

El método utilizado fue la sistematización de experiencias del grupo de estudiantes de posgrado que inició el último año de formación en la especialidad de psiquiatría el primero de abril de 2020.

Posteriormente los relatos fueron leídos en forma conjunta debido al valor que el equipo otorgó a la instancia de compartir las diferentes experiencias. Cada autor seleccionó el fragmento que consideró más relevante de su relato, siendo el orden de aparición de las citas adaptado al hilo conductor del trabajo.

\section{Resultados}

A continuación, se exponen los fragmentos de los relatos que fueron elegidos, y que representan la vivencia del equipo de estudiantes de posgrado del último año de psiquiatría durante el brote de covid-19 en el Hospital Vilardebó.

Me reúno con mi docente en el patio interno del hospital, como acordamos. «iCómo estás hoy?», me pregunta, y yo no sé bien qué responder. Levanto los hombros en gesto de «no sé», mientas el tapabocas tapa la mueca rara de mi cara. Vamos juntas a los vestuarios y nos aprontamos para ir a la sala, primero una y después la otra. Nos observamos entre nosotras mientras hacemos una check list mental del paso a paso, porque nos da miedo equivocarnos. Mameluco, zapatones, tapabocas N95, gorra, sobretúnica, guantes. Las antiparras las llevamos en la mano hasta el momento de entrar a la sala. Yo todavía no aprendí cómo usarlas y ver bien al mismo tiempo. Vamos con cuidado por donde nos marcan las señales que pintaron en el piso del hospital hace unos días. Es todo nuevo y un poco confuso. Ya voy sintiendo cómo mi cuerpo está tensionado; pienso que es por el mameluco, o no, pero entiendo el porqué de la cefalea cuando llego a casa. Llegamos a la antesala y nos dirigimos a enfermería a escuchar las novedades del día. Hoy las noticias no son buenas. Nos cuentan que llegaron los resultados de la última tanda de hisopados y que tres de nuestros pacientes fueron trasladados a otra sala, porque fueron positivos. Nos miramos con tristeza: uno de ellos tenía todo pronto para irse de alta. Vamos a entrar a la sala. Una compañera me dijo que si le pongo jabón a la antiparra, no se empaña tanto, así que pruebo. Me pongo la antiparra con jabón, segundo par de guantes, y estamos prontas para pasar visita. Le pedimos al seguridad que nos abra la reja.*

Este año nos tocó atravesar algo que jamás hemos imaginado vivir [...] Una situación que atacaba al mundo entero. El miedo y la incertidumbre ganaron protagonismo. Nos tocó sacar fuerzas y hacer de lado nuestra propia angustia para poder empatizar con la vulnerabilidad de nuestros pacientes, aun estando llenos de miedos [...] Fui contagiada de covid-19 en mi lugar de trabajo. Me tocó vivir algo único que jamás hubiera imaginado; la sensación de tener en mi cuerpo un virus desconocido, al cual el mundo entero le estaba temiendo, fue una experiencia intensa y difícil de trasmitir [...] Trabajo de introspección y crecimiento personal, con la ayuda de mis seres queridos, a través de redes sociales, pude conocer una parte de mí que se encontraba latente, aprendiendo y reaprendiendo. **

... la rotación al Hospital Vilardebó para cursar el último año. En condiciones normales, las dos palabras que pueden sintetizar o resumir esa instancia en cualquier estudiante serían: adaptación e incertidumbre; palabras o
Trabajo original

* LG, residente de psiquiatria.

** VGF, residente de psiquiatria. 


\section{Trabajo original}

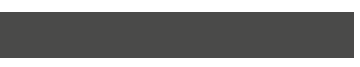

* $\mathrm{DH}$, residente de psiquiatria.

** SM y MR, posgrados de psiquiatria.

*** MK, residente de psiquiatria. sentimientos que se vieron profundizados por los efectos de la pandemia [...] «foco Vilardebó», con lo que se profundizó la incertidumbre [...] Este período se caracterizó fundamentalmente por la ausencia del trabajo en conjunto con compañeros pares y la utilización de un equipo de protección personal (EPP), con las dificultades que este último me generó, principalmente para poder realizar una entrevista y examen psiquiátrico de forma adecuada [...] predominaban las actividades asistenciales, pasando lo académico a un plano virtual, lo que me llevaba a la preocupación por temor a perder la práctica. El denominador común de este último año creo que es el dinamismo y los constantes cambios en el funcionamiento a causa de la evolución de la pandemia a nivel nacional, por lo que hasta el día de hoy la incertidumbre y adaptación siguen presentes en cada uno de nosotros.*

... se nos comunicó que por el momento y hasta nuevo aviso quienes cursamos en la modalidad de posgrado (es decir, sin cargo de residente) no podríamos continuar concurriendo al hospital [...] Esta noticia nos generó sentimientos encontrados. Por un lado, implicó cambiar nuestros planes, poner una especie de pausa llena de incertidumbre, sin saber cuándo finalizaría y podríamos retomar nuestras actividades curriculares. Sintiendo, de una forma muy ingenua quizás, que los conocimientos hasta entonces adquiridos podían esfumarse rápidamente, podía perderse la práctica, el entrenamiento e incluso sintiendo temor de no poder terminar de cursar el año [...] No todo fue negativo, ya que frente a la particular situación mundial que nos llenaba de incertidumbre y miedo; el no tener que salir todos los días a utilizar el transporte público, asistir pacientes, mantener contacto con otras personas fue de alguna manera un privilegio. Pudimos quedarnos en un lugar seguro $y$ protegido durante un tiempo tan particular. Disfrutamos del tiempo libre en nuestros hogares, dedicamos tiempo a actividades que en general se realizan en los espacios libres entre el trabajo y las actividades curriculares del posgrado [...] A todos nos afectó de diferente manera esta experiencia. Hemos aprendido y también hemos sufrido distintas cosas; crecimos y seguramente salgamos más fortalecidos con toda esta experiencia.**

Sentimiento de mucha soledad y desamparo. No quería salir, me quería quedar y trabajar desde casa, donde estaba segura y no me exponía a riesgos. A riesgos de contagio, pero también ver lo que pasaba. La angustia que generaba exponerse a ver lo que pasaba, el choque con la realidad, los ómnibus vacíos, las personas con tapaboca, sin poder vernos las caras, los comercios cerrados. Un pueblo un poco fantasma, a cara tapada. Al menos si estaba adentro no lo veía, solo podía sentir en función de mis propias ideas, o imaginario; sí se materializaba cuando me tocaba venir al hospital.***

Angustia fue la emoción que primó al enfrentar el foco epidemiólogo en el hospital, lo que implicó en primera instancia la cuarentena durante la espera de resultados, el alejamiento de seres queridos por temor a perjudicar su salud, y posteriormente el trabajo asistencial sin mis compañeros y con nuevos docentes. En pocos días desarrollé asistencia en sectores diferentes de un hospital del cual no conocía aún su funcionamiento y la forma de desarrollar mi rol de residente [...] Más que la incomodidad del EPP, el «alejamiento» que impuso con el paciente. Rápidamente cambié de sector [...] al comienzo me generó una gran angustia y un sentimiento de impotencia, valorando el esfuerzo en ese contexto de continuar enseñando $y$ aprendiendo [...] Me sentí egoísta también al quejarme sobre mi situación sabiendo que al mismo tiempo gente enfermaba, se aislaba de sus familias y muchos perdían su empleo [...] Lo negativo, el trabajo aislado sin mis compañeros, la sensación de haber olvidado todo conocimiento adquirido previamente, la situación abrumadora. Lo positivo, la 
adaptación, enfocarnos en poner lo mejor de nosotros para el bien de nuestros pacientes, $y$ progresivamente volver al trabajo en equipo, retomar actividades académicas y reforzar la vocación por esta hermosa e inigualable especialidad.*

... el tercer y último año de posgrado es un momento que ha estado siempre presente como algo que se sabe latente y cargado de expectativas. Es el año en que se define si se está preparado para ejercer la profesión elegida [...] La incertidumbre era horizontal. Pero la vivencia del otro desde la sala de un hospital, en situación de vulnerabilidad, exigía la postergación y redirección de la propia angustia, para el apoyo y acompañamiento de quienes no estaban allí por elección [...] La flexibilidad frente al cambio y la receptividad frente a las nuevas demandas y a la vivencia de otros son aprendizajes valiosos que trajo consigo esta situación inesperada. **

\section{Discusión}

La pandemia de covid-19 ha afectado no solo la salud física, sino también la salud mental de una proporción de la población mundial, modificando sustancialmente la vida cotidiana de las personas. Nos hemos encontrado este año con una problemática de impacto mundial, que ha repercutido de forma importante en la labor de educandos y trabajadores de la salud.

La llegada de la pandemia pareció tomar por sorpresa a la mayoría de las instituciones de la salud a nivel mundial, a pesar de las múltiples advertencias y signos como presagios y aun a pesar de contar con los elementos de protección personal; se instaló en los trabajadores una gran preocupación por el contagio, la estigmatización y la transmisión del virus a familiares. ${ }^{9}$

El SARS-CoV-2 obligó a los profesionales de la salud a vivir en una circunstancia des- conocida e inesperada y en un entorno muy diferente al habitual, en ocasiones separados de sus seres queridos, lo que resulta en un alto costo emocional. El incremento en la autoexigencia para responder a las demandas que produce la pandemia conlleva cansancio físico y psíquico, que a su vez incrementa los cuadros de estrés, ansiedad y depresión. Existen varios estudios sobre las implicancias emocionales en los médicos en el contexto de una pandemia, siendo los síntomas de irritabilidad, insomnio, clinofilia y elementos de estrés postraumático los más reportados. ${ }^{9}$ Nuestro equipo no fue ajeno a esta realidad, identificándonos con algunos de los síntomas mencionados.

Como hemos referido, no es la primera vez que nuestro país se enfrenta a una epidemia que amenaza la salud de nuestra población. Hemos encontrado grandes similitudes entre las medidas descritas que se tomaron durante la gripe española o anteriores epidemias, ${ }^{5,6}$ con las medidas implementadas en la pandemia actual, incluso 100 años después de la más reciente, principalmente en lo referente a la necesidad de realizar modificaciones en lo curricular y académico. No encontramos referencias específicas en cuanto a medidas y repercusiones a nivel de la asistencia en salud mental.

En lo que respecta a la asistencia en salud mental durante la pandemia actual, hemos visto cómo el funcionamiento del hospital en el que nos desempeñamos debió ser modificado por completo.

Las características habituales (previas a la pandemia) de las instalaciones del Hospital Vilardebó y su dinámica de funcionamiento (salas compartidas, patios y comedores comunes), así como las actividades grupales que promueven la interacción entre pacientes, incrementaban el riesgo de transmisión viral. Por otro lado, las características de algunos cuadros clínicos determinaban en los pacientes una mayor dificultad a la hora de comprender la enfermedad y sus formas de contagio, así como para llevar a la práctica las medidas de control sanitario, lo cual representaba un
* $\mathrm{VL}$, residente de psiquiatría. ** SC, residente de psiquiatría. 
desafío para el manejo intrahospitalario del virus. ${ }^{10,11}$ Los cuadros de excitación psicomotriz y la dificultad para mantener el distanciamiento físico son un ejemplo de esto. Se sumó la preocupación por una mayor vulnerabilidad de los pacientes frente a un contagio por SARSCoV-2, debido al estilo de vida poco saludable que muchas veces se asocia a los trastornos que afectan la salud mental, evidenciado en gran parte de los usuarios.

Relato similar en cuanto a las problemáticas inherentes a las características del hospital y de sus pacientes surge de la experiencia vivida en un centro hospitalario de salud mental en Wuhan en contexto del brote de covid-19 en febrero de $2020 .{ }^{10}$ Nos encontramos con múltiples estrategias parecidas implementadas con el fin de contener los contagios intrahospitalarios y el reingreso del virus desde el exterior:

$\mathrm{Al}$ igual que en nuestro hospital, fue necesario crear instalaciones para el aislamiento de pacientes sospechosos y ya diagnosticados.

Se implementó la utilización de equipos de protección específicos, lo que en muchos casos implicó una barrera extra a la hora de establecer el vínculo médico-paciente.

Como en nuestro hospital, fueron suspendidas las actividades grupales y las visitas a los pacientes ya ingresados.

La suspensión de la electroconvulsoterapia también fue una medida descrita en centros de salud mental de otros países. ${ }^{11}$

Todos estos aspectos mencionados dificultaron, según lo referido en artículos de otras partes del mundo ${ }^{10-12}$ y en nuestra experiencia, la instancia de hospitalización y la rapidez con la que los pacientes se recuperan de una forma íntegra, impactando en la forma de trabajo y en la relación médico-paciente.

La imposibilidad de dar altas a pacientes ya compensados, la nueva realidad de la suspensión de las visitas, el distanciamiento físico, y el no contar con todas las herramientas disponibles para la recuperación íntegra de los pacientes y que permitiera acortar las instancias hospitalarias implicaron para nosotros una gran movilización y también mucha angustia.

A continuación, nos enfocamos en la experiencia particular de nuestro grupo de trabajo: docentes y estudiantes de la Cátedra de Psiquiatría de la Facultad de Medicina de la Udelar (Uruguay) en el Hospital Vilardebó, comparándola con la experiencia en servicios de salud mental de otros países.

Este año nos encontramos no solo frente a un hospital con el que gran parte del equipo no estaba familiarizado, sino además frente a una situación nueva y desconocida para todos. Nuestro rol de estudiantes y psiquiatras en formación se vio modificado ante la necesidad de brindar asistencia de la mano de nuestros docentes, quienes también debieron tomar un rol predominantemente asistencial. Tuvimos que adaptarnos a estos nuevos roles que nos tocó desempeñar, poniendo en práctica las herramientas y conocimientos adquiridos hasta el momento y tomando decisiones basándonos en la premisa del cuidado hacia uno y hacia los otros (compañeros del servicio, otros trabajadores de la salud y por supuesto, pacientes), esperando hacer lo mejor posible para evitar los contagios.

Si bien la incertidumbre y la sensación de soledad eran los sentimientos que predominaban, también sentíamos confianza en que todo lo interrumpido y modificado era por un bien mayor y por la necesidad ineludible de priorizar lo asistencial en atención a nuestros pacientes.

Hemos encontrado similitudes entre las medidas implementadas por nuestra unidad docente y las de otros servicios de formación médica en el mundo. Como ejemplo, mencionamos al Departamento de Psiquiatría de la Universidad de Oviedo, España. Al igual que nosotros, debieron realizar modificaciones en las actividades académicas y enfocar la tarea diaria en lo asistencial. El cambio de roles es un hecho también descrito en dicha institución. ${ }^{12}$

La pandemia determinó la necesidad de interrumpir nuestro calendario académico y reorganizarlo. $\mathrm{Al}$ tener que suspender las 
actividades grupales presenciales, surgieron como gran herramienta las instancias virtuales, que representaron no solo una forma de continuar nuestra formación, sino también una forma de mantenernos en contacto como grupo. Estas instancias servían para calmar la sensación de soledad. El intercambio de ideas y sentimientos, con la posibilidad de poner en palabras la angustia y nuestras distintas vivencias individuales, en momentos de tanto miedo e incertidumbre, nos permitió sentirnos validados y más acompañados.

Frente al deseo de relatar estas vivencias, nos surgió la curiosidad de conocer la experiencia de estudiantes de posgrado de especialidades médicas en otras partes del mundo, identificando que aquellas eran similares, independientemente de las distancias culturales y de los distintos idiomas. En diferentes lugares del planeta, personas que realizaban nuestra misma tarea enfrentaban una situación similar, sentían la misma incertidumbre y buscaban generar conocimientos que les permitieran salir fortalecidas. ${ }^{10-12}$

\section{Conclusiones}

La pandemia de covid-19 nos encontró cursando nuestro tercer y último año de formación como posgrados de psiquiatría, debiendo adaptar nuestra labor hospitalaria, en lo asistencial y académico, a esta nueva realidad.

Los servicios de salud y las unidades docenteasistenciales han enfrentado la situación actual con modificaciones estructurales y estrategias asistenciales muy similares, en lugares muy distintos.

Evidenciamos también grandes similitudes en las medidas implementadas a nivel de salud pública e institucional en Uruguay, entre la pandemia de gripe española y la actual pandemia de covid-19, que evidencian un panorama de estrategias generales equivalente, a pesar de haber transcurrido un siglo entre los distintos sucesos.
A nivel vivencial, en comparación con estudiantes de posgrado de otros centros de salud en el mundo, se destaca la semejanza en la percepción emocional frente a la situación epidemiológica, así como en las estrategias de afrontamiento individual y colectivo puestas en marcha.

A pesar de las dificultades y repercusiones emocionales que aún conlleva esta pandemia, hoy podemos decir que también significó para nosotros una oportunidad de reflexión personal y colectiva. Como grupo de pares y grupo de trabajo, pudimos vernos fortalecidos gracias a las múltiples instancias de diálogo, con grandes aprendizajes en lo que respecta a nuestra capacidad de adaptación y a la importancia del trabajo en equipo. A su vez, esta nueva realidad permitió que tanto el equipo de salud como los pacientes compartiéramos una experiencia en común, lo que generó un sentimiento colectivo de fraternidad.

\section{Agradecimientos}

A José Luis González, escritor y dramaturgo, por su lectura atenta, sugerencias y correcciones.

A nuestras docentes Margarita Wschebor, Soledad Brescia, Lía Redes, Paola Pereira y Viviana Porto, que transitaron esta experiencia con nosotros, nos impulsaron a escribir y nos guiaron en cada etapa de la elaboración de este artículo.

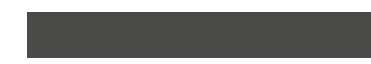


Trabajo original

\section{Referencias bibliográficas}

1. Ministerio de Salud, División Epidemiología. Covid-19. Recomendaciones técnicas para el manejo de casos. Actualización al 26 de febrero de 2020. Disponible en: $<$ www.anep.edu.uy/sites/default/files/ images/2020/noticias/marzo/200313/Recomendaciones\%20COVID19\%202702\%20 MSP.pdf>. (Consulta: set. 2020).

2. Cronología de la respuesta de la OMS a la COVID-19. 2020. Disponible en: $<$ www.who.int/es/news-room/detail/2906-2020-covidtimeline $>$. (Consulta: 27 de setiembre de 2020).

3. COVID-19 Dashboard by the Center for Systems Science and Engineering (CSSE) at Johns Hopkins University (JHU) [Internet]. 2020. Disponible en: <coronavirus.jhu.edu/map.html>. (Consulta: 26 octubre de 2020 ).

4. Informe de situación en relación al coronavirus COVID-19 en Uruguay del 8/4/20 [Internet]. Presidencia de la República, Sistema Nacional de Emergencias (SINAE). 2020. Disponible en: <www.gub. uy/sistema-nacional-emergencias/comunicacion/comunicados/informe-situacionrelacion-coronavirus-covid-19-uruguaydel-8420>. (Consulta: set. 2020).

5. Mañé Garzón F. Teodoro M. Vilardebó (1803-1857): primer médico uruguayo. Montevideo: Academia Nacional de Medicina del Uruguay; 1989. $360 \mathrm{pp}$.

6. Serrón V. Epidemia y perplejidades médicas: Uruguay, 1918-1919. História, Ciências, Saúde-Manguinhos 2011; 18(3):701-721. Disponible en: <scielo. br/pdf/hcsm/v18n3/06.pdf>. (Consulta: oct. 2020).
7. Valdez-García JE, López Cabrera MV, Jiménez Martínez MA, Díaz Elizondo JA, Dávila Rivas JA, Olivares Olivares SL. Me preparo para ayudar: respuesta de escuelas de medicina y ciencias de la salud ante COVID-19. Inv Ed Med 2020; 9(35):85-95. doi: 10.22201/ facmed.20075057e.2020.35.20230

8. Herrera-Añazco $P$, Toro-Huamanchumo CJ. Educación médica durante la pandemia del COVID-19: iniciativas mundiales para el pregrado, internado y el residentado médico. Acta Med Peru 2020; 37(2):169-75. doi: 10.35663/ amp.2020.372.999

9. Alvarez PE, Castiblanco F, Correa AF, Guio AM. COVID-19: médicos, gastroenterología y emociones. Rev Col Gastroenterol 2020; 35(Suppl 1):64-68. doi: 10.22516/25007440.546

10. Xiang YT, Zhao YJ, Liu ZH, Li XH, Zhao N, Cheung T, et al. The COVID-19 outbreak and psychiatric hospitals in China: managing challenges through mental health service reform. Int $\mathrm{J}$ Biol Sci 2020; 16(10):1741-44. doi: 10.7150/ ijbs. 45072

11. Hernández-Huerta $D$, Alonso-Sánchez EB, Carrajo-Garcia CA, MontesRodríguez JM. The impact of COVID-19 on acute psychiatric inpatient unit. Psychiatry Res 2020; 290:113107. doi: 10.1016/j.psychres.2020.113107

12. Dal Santo F, Rodríguez-Revuelta J, García-Portilla MP, Bobes J. Psychiatry residency during the COVID-19 pandemic: navigating uncharted waters. Asian J Psychiatr 2020; 53:102214. doi: 10.1016/j. ajp.2020.102214 